\title{
An audit of the management of oesophageal stricture in children in Durban, KwaZulu-Natal Province, South Africa
}

\author{
O S Moumin, ${ }^{1}$ MB ChB, High Dip Surgery (SA), FCS (SA); G P Hadley, ${ }^{2}$ MB ChB FRCS (Edin.), FCS (SA) \\ ${ }^{1}$ Department of Surgery, Nelson R Mandela School of Medicine, University of KwaZulu-Natal, Durban, South Africa \\ ${ }^{2}$ Professor Emeritus, Department of Paediatric Surgery, Nelson R Mandela School of Medicine, University of KwaZulu-Natal, Durban, \\ South Africa
}

Corresponding author: O S Moumin (omarmoumin@gmail.com)

\begin{abstract}
Objective. To determine the outcome of the endoscopic management of oesophageal strictures (OSs) of varying aetiology in children in a tertiary centre.

Methods. A retrospective chart review was conducted of all children aged $<14$ years at department of paediatric surgery who underwent endoscopic dilatation of OSs at Inkosi Albert Luthuli Central Hospital in Durban, KwaZulu-Natal Province, South Africa, between July 2002 to December 2010. Management status at 3 years after presentation was used to define outcome.

Results. A total of 39 patients aged between 1 month and 13 years were reviewed, and 18 (46\%) were males. Thirty-six (92.3\%) were black South Africans, and 11 (28\%) were HIV-infected. Among the types of strictures, postoperative (35\%) and corrosive (30.8\%) OSs were more prevalent than HIV-related (20.5\%) OSs. The mean number of dilatations needed per patient was 7.3, and those patients with corrosive OSs needed more dilatation sessions (median (interquartile range)) than others (10 (5 - 14) v. $6.5(5$ - 10)). Out of 287 attempted dilatations, oesophageal perforations occurred in $8(2.8 \%)$ cases. Mitomycin C was applied topically in $4(10.3 \%)$ patients, with excellent results. A good response to endoscopic treatment was seen in $27(69 \%)$ cases. The worst outcome was noted in HIV-infected patients.

Conclusion. Endoscopic treatment of OSs in children yields good results and has a low rate of treatable complications. Patients should be treated on an individual basis, even if they have strictures of the same aetiology.
\end{abstract}

S Afr J Child Health 2017;11(2):71-74. DOI:10.7196/SAJCH.2017.v11i2.1179

Oesophageal strictures (OSs) are common in resource-poor countries. In children, OSs may result from surgery to the oesophagus, such as repair of oesophageal atresia, or following repeated sclerotherapy for oesophageal varices; however, OSs are most commonly caused by chemical injuries. ${ }^{[1]}$ OSs are occasionally seen in children with untreated gastro-oesophageal reflux, most notably in those with neurological impairment, and also after oesophageal infections, especially in HIV-positive children. ${ }^{[1-3]}$ The goals of management are to relieve dysphagia, ensure adequate nutrition for growth and development, and to prevent aspiration pneumonia and recurrence of the stricture by oesophageal dilatation, stenting, or replacement surgery. ${ }^{[4,5]}$

There are several parameters that have been used to define the outcome of patients suffering from OSs, of which the clinical resolution of dysphagia is considered the most relevant. Many patients report significantly improved symptoms shortly after dilatation, but these gradually worsen over time. ${ }^{[1,4,6]}$ The aim of this study was to describe the aetiology and outcomes of the management of OSs in children in Durban, KwaZulu-Natal Province (KZN), South Africa (SA).

\section{Methods}

The study design was approved by the Biomedical Research Ethics Committee of the University of KwaZulu-Natal (ref. no. BE044/14), the Department of Health and the management of Inkosi Albert Luthuli Central Hospital. A retrospective chart review was conducted of all paediatric patients aged $<14$ years, who had been admitted for management of OSs at Inkosi Albert Luthuli Central Hospital in Durban, KZN, SA from July 2002 to December 2010. Management status at 3 years after presentation was used to define outcome. Data collected from the patients' files were manually entered into a Microsoft
Excel spreadsheet. Patient demographics included age, gender, race, comorbidities, aetiological factors, diagnostic investigations, type of endoscope used, location and number of strictures, duration of treatment, complications, recurrence, adjuvant therapy, and patient outcomes. Diagnosis of OS was made endoscopically and radiologically. Operative procedures were performed under general anaesthesia by different paediatric surgeons and trainees.

\section{Results}

Thirty-nine patients were identified and included in our review. Their ages ranged from 1 month to 13 years, and there were 18 (46\%) males and $21(54 \%)$ females. Most participants were black South Africans (36 (92\%)), in keeping with the demographics of the population served. Eleven children (28\%) were HIV-infected, (5\%) were HIVexposed, and 23 (59\%) children had not been tested for HIV. Strictures secondary to surgical correction of oesophageal atresia (14 (35.9\%)) were the most common, followed by OSs due to corrosive injury (12 $(30.8 \%))$. HIV-related strictures were seen in $8(21 \%)$ children, while gastro-oesophageal reflux (2 (5\%)), and foreign body (FB) ingestion (3 $(7.6 \%))$ were less common.

The most common stricture site was the middle-third of the oesophagus (51\%), with $33.3 \%$ in the upper-third, and $16 \%$ in the lower-third. Most of the patients had a single stricture (36 (92\%)). OSs secondary to acid ingestion were in the upper- and middle-thirds of the oesophagus, and those following alkali ingestion were in the lower-third of the oesophagus. There was no statistical relationship between the cause of the OS and the site thereof (Table 1).

Dysphagia was reported by 32 patients $(82 \%)$ on presentation. Seven (18\%) patients reported no dysphagia, of whom five were treated for oesophageal atresia and were still breastfeeding. Dysphagia was most frequent in patients with alkali- and HIV- 
Table 1. Relation between the causes and sites of oesophageal strictures

\begin{tabular}{llllll}
\hline Cause of stricture & $\begin{array}{l}\text { Upper-third, } \\
\boldsymbol{n}(\%)\end{array}$ & $\begin{array}{l}\text { Middle-third, } \\
\boldsymbol{n}(\%)\end{array}$ & $\begin{array}{l}\text { Lower-third, } \\
\boldsymbol{n}(\%)\end{array}$ & $\begin{array}{l}\text { Total, } \\
\boldsymbol{N}\end{array}$ & $\boldsymbol{p}$-value \\
\hline Acid & $3(50)$ & $3(50)$ & $0(0)$ & 6 & \\
Alkali & $2(33)$ & $1(17)$ & $3(50)$ & 6 & \\
Post-surgery & $4(29)$ & $10(71)$ & $0(0)$ & 14 & \\
GORD & $0(0)$ & $1(50)$ & $1(50)$ & 2 & \\
HIV Complications & $3(38)$ & $4(50)$ & $1(13)$ & 8 & \\
FB & $1(33)$ & $1(33)$ & $1(33)$ & 3 & \\
Total & $13(34)$ & $20(51)$ & $6(15)$ & 39 & 0.08 \\
GORD = gastro-oesophageal reflux disease; FB = foreign body. & & &
\end{tabular}

related strictures although this observation was not statistically significant (Table 2).

Contrast oesophagograms were used in the diagnosis and in the follow-up of most patients $(32(82 \%))$. The mean duration of treatment per patient was 29.5 months. Overall, 287 dilatations were performed in 39 patients using either Savary-Gilliard or balloon dilators. The median (interquartile range (IQR)) number of dilatations per patient was highest for those with acid- and alkali-related injuries (10 (5 - 14) and 6.5 (5 - 10), respectively), and lowest for those related to FB ingestion $(2.5(2-3))$ (Table 3$)$.

Perforation occurred in $8(3.1 \%)$ cases, out of 287 attempted dilatations. Over a 3 -year follow-up period, recurrence of the OS was observed in $12(32.4 \%)$ patients and was most frequent following alkali ingestion (50\%). Mitomycin C was applied locally in $4(10.3 \%)$ patients with a mean (standard deviation (SD)) of 8.7 (2.8) applications per patient. Mitomycin C application was associated with stricture resolution in all patients.

Stenting was performed in 2 (5.1\%) patients: one following acid ingestion with failure to maintain a lumen by dilatation, and the other in an HIV-infected child with a presumed vasculopathy following perforation during dilatation. Oesophageal replacement was performed for $3(7.6 \%)$ patients following caustic injury. Five (13\%) patients died: two following perforations, including the HIV-infected patient who underwent oesophageal stenting; one following surgical replacement of the oesophagus; and two from unrelated sepsis. Seven (18\%) patients were lost to followup, and three (8\%) were referred to general surgeons for follow-up (Table 4).

\section{Discussion}

The causes and prevalence of OSs in the paediatric population varies with the geographical region, and management should be tailored to the available resources and the prevalent socio-educational environment. Well-trained medical and nursing teams, with properly equipped neonatal intensive care units, have resulted in improved survival of neonates with congenital malformations, including oesophageal atresia. Postoperative morbidity now accounts for a significant proportion of the burden of the disease, and despite the recent refinements of operative techniques and improvements in perioperative management, anastomotic stricture after repair of oesophageal atresia remains frequent and develops in nearly $40 \%$ of operated patients. ${ }^{[7-10]}$ Improved survival has increased the number of children with oesophageal anastomotic strictures referred for treatment, and they now account for $35.9 \%$ of patients with OSs in our unit. Strictures secondary to the surgical correction of oesophageal atresia often show a good response to endoscopic treatment augmented by an anti-reflux procedure.

In developing countries, caustic ingestion is still frequent among children, and causes OSs due to the circumferential injury extending into the muscularis propria, followed by subsequent fibrosis. ${ }^{[5,11,12]}$ Such strictures are often complex, multisegmented, rigid, tortuous, and extensive. Owing to their refractory nature, they tend to be difficult to dilate. ${ }^{[4]}$ In our cohort, we noted that the median number of dilatations was the highest for the caustic injury group.

HIV and its complications have become a massive clinical burden in developing countries. Candidiasis is the most common cause of oesophageal symptoms in HIVinfected patients and repeated episodes progressively damage the oesophageal mucosa, resulting in scarring, fibrosis, and stricture formation. ${ }^{[13,15]}$ Viral oesophagitis, especially due to cytomegalovirus (CMV) infection, and idiopathic oesophageal ulcers are also important causes of oesophageal strictures in HIV-infected children. ${ }^{[16]}$ In many HIV-infected patients no specific secondary pathology can be identified and HIV-related vasculitis has been suggested as the underlying cause of OS formation. In adults, gastro-oesophageal reflux increases in patients on HAART and this may further contribute to idiopathic oesophageal strictures in the lower third of oesophagus in HIV patients. ${ }^{[14,17,18]}$ Treatment of OSs caused by the complications of HIV, infection has been infrequently reported. Eight of our patients (20.5\%) presented with OSs related to HIV. The strictures were mainly in the proximal- and middle-thirds of the oesophagus and we noted that the prognosis of these patients was affected negatively and management became more difficult for these patients if they have low CD4 counts.

OSs related to gastro-oesophageal reflux are the consequence of repeated insults of the oesophageal mucosa with gastric acids, which are normally limited by a competent lower oesophageal sphincter and rapidly cleared by normal oesophageal peristalsis.

Table 2. The relation between the degree of dysphagia and the cause of stricture

\begin{tabular}{|c|c|c|c|c|c|c|c|}
\hline & $\begin{array}{l}\text { Without } \\
\text { dysphagia, } n(\%)\end{array}$ & $\begin{array}{l}\text { Dysphagia to } \\
\text { solids, } n(\%)\end{array}$ & $\begin{array}{l}\text { Dysphagia to } \\
\text { semisolids, } n(\%)\end{array}$ & $\begin{array}{l}\text { Dysphagia to } \\
\text { liquids, } n(\%)\end{array}$ & $\begin{array}{l}\text { Dysphagia to } \\
\text { saliva, } n(\%)\end{array}$ & $\begin{array}{l}\text { Not assessed for } \\
\text { dysphagia, } n(\%)\end{array}$ & Total, $N$ \\
\hline Acids & $1(17)$ & $2(33)$ & $1(17)$ & $1(17)$ & $1(17)$ & $0(0)$ & 6 \\
\hline Alkali & $0(0)$ & $2(33)$ & $2(33)$ & $1(17)$ & $1(17)$ & $0(0)$ & 6 \\
\hline Post-surgery & $0(0)$ & $2(14)$ & $3(21)$ & $4(29)$ & $0(0)$ & $5(35)$ & 14 \\
\hline GORD & $0(0)$ & $2(100)$ & $0(0)$ & $0(0)$ & $0(0)$ & $0(0)$ & 2 \\
\hline HIV complications & $0(0)$ & $3(38)$ & $1(13)$ & $3(38)$ & $0(0)$ & $1(13)$ & 8 \\
\hline FB & $0(0)$ & $3(100)$ & $0(0)$ & $0(0)$ & $0(0)$ & $0(0)$ & 3 \\
\hline Total & $1(3)$ & $14(36)$ & $7(18)$ & $9(23)$ & $2(5)$ & $6(15)$ & 39 \\
\hline
\end{tabular}


Table 3. The relation between the cause of OSs, and the need for endoscopies and the number of dilatations

\begin{tabular}{llllll}
\hline \multirow{2}{*}{ Cause of stricture } & & \multicolumn{2}{l}{ Number of endoscopies } & & \multicolumn{2}{l}{ Number of dilatations } \\
Acid & Median & IQR & & Median & IQR \\
Alkali & 6 & 10.5 & $5-16$ & 10 & $5-14$ \\
Postoperative & 6 & 9 & $7-12$ & 6.5 & $5-10$ \\
GORD & 14 & 5.5 & $2-8$ & 4.5 & $2-7$ \\
HIV-related & 2 & 3 & $3-3$ & 2.5 & $2-3$ \\
FB & 8 & 6.5 & $2.5-18$ & 5 & $3-16.5$ \\
FB battery & 2 & 3.5 & $3-4$ & 2.5 & $2-3$ \\
Total & 1 & 2 & $2-2$ & 1 & $1-1$ \\
& 39 & 6 & $3-12$ & 5 & $3-10$
\end{tabular}

OS = oesophageal stricture; IQR = interquartile range; GORD = gastro-oesophageal reflux disease; $\mathrm{FB}$ = foreign body.

Table 4. Management outcomes at 3 years following presentation $(N=39)$

\begin{tabular}{llllll}
\hline & \multicolumn{5}{c}{ Outcome, $\boldsymbol{n}(\%)$} \\
\cline { 2 - 6 } HIV status & Discharged & Died & Defaulted & Referred & Total \\
\hline Negative & $19(68)$ & $2(7)$ & $6(21)$ & $1(4)$ & 28 \\
Positive & $5(45)$ & $3(27)$ & $1(9)$ & $2(18)$ & 11 \\
Total & $24(62)$ & $5(13)$ & $7(18)$ & $3(8)$ & 39
\end{tabular}

Most of these strictures are found in the distal-third of the oesophagus. ${ }^{[19]}$ In this study, $5 \%$ of OSs were secondary to gastrooesophageal reflux disease. Generally, this type of OS responds well to dilatation, and complete resolution occurs in $70-90 \%$ of cases when dilation is combined with treatment with proton pump inhibitors. ${ }^{[19,20]}$

Children account for about $80 \%$ of cases of FB ingestion. The most frequently ingested FBs are coins, bones, and button batteries, which can damage the oesophagus and lead to strictures. Button batteries are easily swallowed by children and may cause severe injuries due to electrochemical burns when in contact with the oesophageal mucosa, and/or the release of caustic substances when fragmented. ${ }^{[21-23]}$

Dysphagia is the classic presentation of an OS, which may occur when more than half of the oesophageal lumen is narrowed. Children on a liquid diet generally present later and, in infants, the dominant symptom may be reluctance to feed. Patients with advanced strictures often fail to thrive and present with respiratory problems, ranging from a cough to recurrent pneumonia. Patient history and clinical examination can determine the cause of dysphagia in $>75 \%$ of patients. ${ }^{[3,4]}$ In our study, dysphagia was the dominant symptom in $85 \%$ of patients.

Contrast studies and fluoroscopy are essential to determine the characteristics of the stricture. Rigid or fibre-optic endoscopy, as well as a biopsy, is necessary to evaluate luminal and mucosal pathology and has the advantage of direct visualisation to determine the location, diameter, length, extent, and possible aetiology of a stricture. ${ }^{[3,5,24]}$

Most OSs can be managed with periodic endoscopic dilatations. Gradual dilatation is essential and the procedure is largely individualised, as the optimal frequency and timing has not been established. The time interval between procedures is based on the effects of the previous dilatations and the recurrence of symptoms. ${ }^{[5]}$ Dilators apply either radial or axial forces, or both. In complex strictures, such as those seen after caustic injury, balloon dilators, which apply a radial force only, are favoured although there are no data to support this view. ${ }^{[6]}$ In our unit, we predominantly use Savary-Gilliard dilators as they are available, affordable, and yield satisfactory results.

The ideal final diameter of the oesophageal lumen after dilatation can be determined by the patients' clinical condition, considering the improvement of dysphagia, nutritional status and extent of normal oesophageal mucosa. Patients were usually discharged when they became asymptomatic and after re-epithelialisation of the lesion had been observed on subsequent endoscopy.

Most strictures are amenable to dilatation, although it has been estimated that 7\% of strictures cannot be successfully dilated and such patients become candidates for oesophageal replacement. ${ }^{[6,25,26]}$

Additional therapy may be attempted in patients with refractory strictures, including topical application of mitomycin
C to the stricture site in an attempt to prevent new collagen formation, which decreases the incidence of recurrence. ${ }^{[12,27]}$ After endoscopic dilatation, mitomycin $\mathrm{C}$ can be applied to the dilatation wound by using a rigid endoscopy ${ }^{[28]}$ All our patients who had mitomycin C applied locally had shown failure of stricture resolution after 10 standard oesophageal dilatations. Following application of mitomycin $\mathrm{C}$, they all had complete resolution of the stricture and were discharged before 3 years of follow up. Mitomycin $\mathrm{C}$ application started as a technique for refractory strictures but has now become routine for chemical injury.

In children, oesophageal perforation remains the most dreaded complication of oesophageal dilatation. Complex OSs (narrower, angulated), especially causticinduced strictures, seem to be associated with an increased risk of oesophageal perforation. ${ }^{[29,30]}$ In our assessment of 287 dilatations, we had 8 perforations $(2.8 \%)$. Early diagnosis is the most important prognostic factor to reduce morbidity and mortality, which is reported to range between $0 \%$ and $33 \%{ }^{[7,29]}$

There are several parameters that have been used to describe the outcome of patients suffering from OSs. Resolution of dysphagia is considered the most relevant parameter but the potential weakness of this endpoint is that many patients with refractory stenosis report significantly improved symptoms shortly after dilatation, but they gradually worsen over time. ${ }^{[7,9]}$ In our study, HIV-infected patients did poorly, compared with those who were either negative or not tested for HIV. All HIV-infected patients who died had established AIDS with a low CD4 count. In these patients, any contribution of the OS to their death, by preventing the ingestion of essential medication, remains speculation.

Successful treatment by dilatation varies from centre to centre and depends mainly on the aetiology. An adequate lumen should be re-established within 6 months to 1 year, with progressively longer intervals between dilatations. ${ }^{[3,7,31]}$ If, during the course of treatment, an adequate lumen cannot be established or maintained, more aggressive intervention should be considered.

\section{Conclusion}

Endoscopic dilatation of OSs often yields good results and has low rates of treatable complications. Patients with OSs secondary to caustic ingestion have higher morbidity and need more dilatation sessions. OSs related to complications of retroviral disease have increased and seem to be difficult to manage. Patients should be treated on an individual basis, even if they have strictures with the same aetiology. 
Acknowledgements. None.

Author contributions. OSM conceptualised the study, acquired and analysed data, and drafted the manuscript. GPH revised the manuscript.

Funding. None.

Conflict of interest. None.

1. Khan KM. Endoscopic management of strictures in pediatrics. Tech Gastrointest Endosc 2013;15(1):25-31. https://doi.org/10.1016/j.tgie.2012.10.002

2. Azizkhan RG, Stehr W, Cohen AP, et al. Esophageal strictures in children with recessive dystrophic epidermolysis bullosa: An 11-year experience with fluoroscopically guided balloon dilatation. Journal of Pediatr Surg 2006;41(1):55-60. https://doi.org/10.1016/j.jpedsurg.2005.10.007

3. Shehata SM, Enaba ME. Endoscopic dilatation for benign oesophageal strictures in infants and toddlers: Experience of an expectant protocol from North African tertiary centre. Afr j Paediatr Surg 21012;9(3):187. https://doi. org/10.4103/0189-6725.104717

4. Ul-Haq A, Tareen F, Bader I, Burki T, Khan N-u-Z. Oesophageal replacement in children with indolent stricture of the oesophagus. Asian J Surg 2006;29(1):1721. https://doi.org/10.1016/s1015-9584(09)60287-6

5. Forte V, Chait P, Sommer D. Endoscopic management of tracheal and esophageal strictures. Semin Pediatr Surg 2003;12(1):71-79. https://doi. org/10.1016/S1055-8586(03)70009-2

6. Chang C-F, Kuo S-P, Lin H-C, et al. Endoscopic balloon dilatation for esophageal strictures in children younger than 6 years: Experience in a medical center. Pediatr Neonatol 2011;52(4):196-202. https://doi.org/10.1016/j. pedneo.2011.05.005

7. Bittencourt PF, Carvalho SD, Ferreira AR, et al. Endoscopic dilatation of esophageal strictures in children and adolescents. Jornal de Pediatria 2006;82(2):127-131. http://dx.doi.org/10.1590/S0021-75572006000200009

8. Mendelson AH, Small AJ, Agarwalla A, Scott FI, Kochman ML. Esophageal anastomotic strictures: Outcomes of endoscopic dilation, risk of recurrence and refractory stenosis, and effect of foreign body removal. Clin Gastroenterol Hepatol 2015;13(2):263-271.e1. https://doi.org/10.1016/j.cgh.2014.07.010

9. Serhal L, Gottrand F, Sfeir R, et al. Anastomotic stricture after surgical repair of esophageal atresia: Frequency, risk factors, and efficacy of esophageal bougie dilatations. J Pediatr Surg 2010;45(7):1459-1462. https://doi.org/10.1016/j. jpedsurg.2009.11.002

10. Koivusalo AI, Pakarinen MP, Rintala RJ. Modern outcomes of oesophageal atresia: Single centre experience over the last twenty years. J Pediatr Surg 2013;48(2):297-303. https://doi.org/10.1016/j.jpedsurg.2012.11.007

11. Contini S, Garatti M, Swarray-Deen A, Depetris N, Cecchini S, Scarpignato C. Corrosive oesophageal strictures in children: Outcomes after timely or delayed dilatation. Digestive Liver Dis 2009;41(4):263-268. https://doi.org/10.1016/j. dld.2008.07.319

12. El-Asmar KM, Hassan MA, Abdelkader HM, Hamza AF. Topical mitomycin C application is effective in management of localized caustic esophageal stricture: A double-blinded, randomized, placebo-controlled trial. J Pediatr Surg 2013;48(7):1621-1627. https://doi.org/10.1016/j.jpedsurg.2013.04.014

13. Lortholary O, Petrikkos G, Akova M, et al. ESCMID* guideline for the diagnosis and management of Candida diseases 2012: Patients with HIV infection or AIDS. Clin Microbiol Infec. 2012;18(Suppl 7):68-77. https://doi org/10.1111/1469-0691.12042

14. Karpelowsky J, Millar AJW. Surgical implications of human immunodeficiency virus infections. Semin Pediatr Surg 2012;21(2):125-135. https://doi org/10.1053/j.sempedsurg.2012.01.005
15. Werneck-Silva AL, Pagliari C, Patzina RA, da Silva WF, Galo LK, Duarte MIS. Su1952 TH17 pathway promotes mucosal host defense against esophageal candidiasis in HIV-infected patients. Gastroenterol 2014;146(5) Suppl 1:S506-S507. https://doi.org/10.1016/s0016-5085(14)61832-1

16. Loveland JA, Mitchell CE, van Wyk P, Beale P. Esophegeal replacement in children with AIDS. J Pediatr Surg 2010;45(10):2068-2070. https://doi. org/10.1016/j.jpedsurg.2010.06.026

17. Wilcox CM. Esophageal disease in the acquired immunodeficiency syndrome: Etiology, diagnosis, and management. Am J Med 1992;92(4):412-421. https:// doi.org/10.1016/0002-9343(92)90272-

18. Bonacini M. Medical management of benign oesophageal disease in patients with human immunodeficiency virus infection. Digest Liver Dis 2001;33(3):294-300. https://doi.org/10.1016/s1590-8658(01)80722-2

19. Zouari M, Kamoun H, Bouthour H, et al. Peptic oesophageal stricture in children: Management problems. Afr J Paediatr Surg 2014;11(1):22-25. https:// doi.org/10.4103/0189-6725.129206

20. Pearson EG, Downey EC, Barnhart DC, et al. Reflux esophageal stricture - a review of 30 years' experience in children. J Pediatr Surg 2010;45(12):23562360. https://doi.org/10.1016/j.jpedsurg.2010.08.033

21. Samad L, Ali M, Ramzi H. Button battery ingestion: Hazards of esophageal impaction. J Pediatr Surg 1999;34(10):1527-1531. https://doi.org/10.1016/ s0022-3468(99)90119-7

22. Lin VY, Daniel SJ, Papsin BC. Button batteries in the ear, nose and upper aerodigestive tract. Int J Pediatr Otorhinolaryngol 2004;68(4):473-479. https:// doi.org/10.1016/j.ijporl.2003.10.020

23. Laugel V, Beladdale J, Escande B, Simeoni U. [Accidental ingestion of button battery.] Archives de Pediatrie 1999;6(11):1231-1235. https://doi.org/10.1016/ s0929-693x(00)86309-5

24. Hamza AF, Abdelhay S, Sherif $\mathrm{H}$, et al. Caustic esophageal strictures in children: 30 years' experience. J Pediatr Surg 2003;38(6):828-833. https://doi. org/10.1016/s0022-3468(03)00105-2

25. Lan LCL, Wong KKY, Lin SCL, et al. Endoscopic balloon dilatation of esophagea strictures in infants and children: 17 years' experience and a literature review. J Pediatr Surg 2003;38(12):1712-1715. https://doi.org/10.1016/j. jpedsurg.2003.08.040

26. De Peppo F, Zaccara A, Dall'Oglio L, et al. Stenting for caustic strictures: Esophageal replacement replaced. J Pediatr Surg 1998;33(1):54-57. https://doi. org/10.1016/s0022-3468(98)90361-x

27. Heran MKS, Baird R, Blair GK, Skarsgard ED. Topical mitomycin-C for recalcitrant esophageal strictures: A novel endoscopic/fluoroscopic technique for safe endoluminal delivery. J Pediatr Surg 2008;43(5):815-818. https://doi. org/10.1016/j.jpedsurg.2007.12.017

28. Olutoye OO, Shulman RJ, Cotton RT. Mitomycin C in the management of pediatric caustic esophageal strictures: A case report. J Pediatr Surg 2006;41(5):e1-e3. https://doi.org/10.1016/j.jpedsurg.2005.12.051

29. Fayek M, Gerdes H. Risks of esophagogastroduodenoscopy and esophageal dilation. Tech Gastrointest Endosc 2008;10(1):2-6. https://doi.org/10.1016/j. tgie.2007.08.004

30. Schmidt SC, Strauch S, Rosch T, et al. Management of esophageal perforations. Surg Endosc 2010;24(11):2809-2813. https://doi.org/10.1007/s00464-0101054-6

31. Pearson FG. Surgical therapy for esophageal disease: Lessons from a master. Ann Thorac Surg 2010;89(6):S2180-S2182. https://doi.org/10.1016/j. athoracsur.2010.03.076 